\title{
On the stability of the heat equation with an initial condition
}

\section{Soon-Mo Jung ${ }^{*}$}

\section{"Correspondence:}

smjung@hongik.ac.kr

Mathematics Section, College of

Science and Technology, Hongik

University, Sejong, 339-701, Korea

\section{Abstract}

In this paper, we prove the generalized Hyers-Ulam stability of the heat equation with an initial condition

$$
\begin{cases}\Delta u(x, t)=u_{t}(x, t) & \left(\text { for all } x \in \mathbb{R}^{n} \text { and } t>0\right), \\ u(x, 0)=g(x) & \left(\text { for all } x \in \mathbb{R}^{n}\right)\end{cases}
$$

in a class of twice continuously differentiable functions under certain conditions.

\section{Introduction}

Let $X$ be a normed space, and let $I$ be an open interval. If for any function $f: I \rightarrow X$ satisfying the differential inequality

$$
\left\|a_{n}(x) y^{(n)}(x)+a_{n-1}(x) y^{(n-1)}(x)+\cdots+a_{1}(x) y^{\prime}(x)+a_{0}(x) y(x)+h(x)\right\| \leq \varepsilon
$$

for all $x \in I$ and for some $\varepsilon \geq 0$ there exists a solution $f_{0}: I \rightarrow X$ of the differential equation

$$
a_{n}(x) y^{(n)}(x)+a_{n-1}(x) y^{(n-1)}(x)+\cdots+a_{1}(x) y^{\prime}(x)+a_{0}(x) y(x)+h(x)=0
$$

such that $\left\|f(x)-f_{0}(x)\right\| \leq K(\varepsilon)$ for any $x \in I$, where $K(\varepsilon)$ is an expression of $\varepsilon$ only, then we say that the above differential equation has the Hyers-Ulam stability.

If the above statement is also true when we replace $\varepsilon$ and $K(\varepsilon)$ by $\varphi(x)$ and $\Phi(x)$, where $\varphi, \Phi: I \rightarrow[0, \infty)$ are functions not depending on $f$ and $f_{0}$ explicitly, then we say that the corresponding differential equation has the generalized Hyers-Ulam stability. (This type of stability is sometimes called the Hyers-Ulam-Rassias stability.)

We may apply these terminologies to other differential equations and partial differential equations. For more detailed definitions of the Hyers-Ulam stability and the generalized Hyers-Ulam stability, refer to [1-8].

Obłoza seems to be the first author who has investigated the Hyers-Ulam stability of linear differential equations (see $[9,10])$. Here, we introduce the result of Alsina and Ger (see [1]): If a differentiable function $f: I \rightarrow \mathbb{R}$ is a solution of the differential inequality $\left|y^{\prime}(x)-y(x)\right| \leq \varepsilon$, where $I$ is an open subinterval of $\mathbb{R}$, then there exists a solution $f_{0}: I \rightarrow \mathbb{R}$ of the differential equation $y^{\prime}(x)=y(x)$ such that $\left|f(x)-f_{0}(x)\right| \leq 3 \varepsilon$ for any $x \in I$. This result was generalized by Miura et al. (see $[11,12])$.

○2013 Jung: licensee Springer. This is an Open Access article distributed under the terms of the Creative Commons Attribution License (http://creativecommons.org/licenses/by/2.0), which permits unrestricted use, distribution, and reproduction in any medium, provided the original work is properly cited. 
In 2007, Jung and Lee [13] proved the Hyers-Ulam stability of the first-order linear partial differential equation

$$
a u_{x}(x, y)+b u_{y}(x, y)+c u(x, y)+d=0,
$$

where $a, b \in \mathbb{R}$ and $c, d \in \mathbb{C}$ are constants with $\Re(c) \neq 0$. It seems that the first paper dealing with the Hyers-Ulam stability of partial differential equations was written by Prastaro and Rassias [14]. For a recent result on this subject, refer to [15].

In this paper, using an idea from the papers $[16,17]$, we investigate the generalized HyersUlam stability of the heat equation with an initial value condition

$$
\begin{cases}\Delta u(x, t)=u_{t}(x, t) & \left(\text { for all } x \in \mathbb{R}^{n} \text { and } t>0\right), \\ u(x, 0)=g(x) & \left(\text { for all } x \in \mathbb{R}^{n}\right)\end{cases}
$$

in the class of radially symmetric functions, where $\Delta$ denotes the Laplace operator. The heat equation plays an important role in a number of fields of science. It is strongly related to the Brownian motion in probability theory. The heat equation is also connected with chemical diffusion, and it is sometimes called the diffusion equation.

\section{Main result}

For a given integer $n \geq 2, x_{i}$ denotes the $i$ th coordinate of any point $x$ in $\mathbb{R}^{n}$, i.e., $x=$ $\left(x_{1}, \ldots, x_{i}, \ldots, x_{n}\right)$. We assume that $t_{1}$ is a constant with $0<t_{1} \leq \infty$, and we define

$$
T:=\left\{t \in \mathbb{R} \mid 0<t<t_{1}\right\} \quad \text { and } \quad|x|:=\sqrt{x_{1}^{2}+\cdots+x_{n}^{2}} \text {. }
$$

Due to an idea from [18, Section 2.3.1], we may search for a solution of (1.1) of the form $u(x, t)=\left(1 / t^{n / 2}\right) v\left(|x| / t^{1 / 2}\right)$ for some function $v$. Based on this argument, we define

$$
\begin{gathered}
U:=\left\{u: \mathbb{R}^{n} \times T \rightarrow \mathbb{R} \mid u(x, t)=\frac{1}{t^{n / 2}} w(r) \text { for all } x \in \mathbb{R}^{n}, t \in T\right. \\
\quad \text { and for some function } w:[0, \infty) \rightarrow \mathbb{R} \text { with } r=\frac{|x|}{t^{1 / 2}} \\
\left.\quad \text { and } \lim _{r \rightarrow \infty} r^{n} w(r)=\lim _{r \rightarrow \infty} r^{n-1} w^{\prime}(r)=0\right\} .
\end{gathered}
$$

Theorem 2.1 Let $\varphi_{1}, \varphi_{2}:[0, \infty) \rightarrow[0, \infty)$ and $\psi: T \rightarrow[0, \infty)$ be functions such that

$$
\begin{aligned}
& D:=\int_{0}^{\infty} \frac{e^{u^{2} / 4}}{u^{n-1}} \int_{u}^{\infty} s^{n-1} \varphi_{1}(s) d s d u<\infty, \\
& c:=\inf _{t \in T} t^{n / 2+1} \psi(t)>0 .
\end{aligned}
$$

Assume that $g: \mathbb{R}^{n} \rightarrow \mathbb{R}$ is a function with $g \in C\left(\mathbb{R}^{n}\right) \cap L^{\infty}\left(\mathbb{R}^{n}\right)$. If a twice continuously differentiable function $u \in U$ satisfies

$$
\begin{cases}\left|\Delta u(x, t)-u_{t}(x, t)\right| \leq \varphi_{1}\left(\frac{|x|}{t^{1 / 2}}\right) \psi(t) & \left(\text { for all } x \in \mathbb{R}^{n} \text { and } t \in T\right) \\ |u(x, 0)-g(x)| \leq \varphi_{2}(|x|) & \left(\text { for all } x \in \mathbb{R}^{n}\right),\end{cases}
$$


then there exist solutions $u_{0}, u_{1}: \mathbb{R}^{n} \times T \rightarrow \mathbb{R}$ of the heat equation and a real number $\gamma$ such that

$$
\begin{aligned}
& \left|u(x, t)-\gamma u_{0}(x, t)\right| \leq \frac{c D}{t^{n / 2}} e^{-|x|^{2} / 4 t}, \\
& \left|\int_{\mathbb{R}^{n}} u(x-y, t) g(y) d y-\gamma u_{1}(x, t)\right| \leq(4 \pi)^{n / 2} c D \int_{\mathbb{R}^{n}} u_{0}(x-y, t)|g(y)| d y
\end{aligned}
$$

for all $x \in \mathbb{R}^{n}$ and $t \in T$ with $|x| / t^{1 / 2}>0$, where

$$
u_{0}(x, t):=\frac{1}{(4 \pi t)^{n / 2}} e^{-|x|^{2} / 4 t} \quad \text { and } \quad u_{1}(x, t):=\int_{\mathbb{R}^{n}} u_{0}(x-y, t) g(y) d y
$$

Proof Since $u(x, t) \in U$, there exists a function $w:[0, \infty) \rightarrow \mathbb{R}$ such that

$$
u(x, t)=\frac{1}{t^{n / 2}} w(r)
$$

for any $x \in \mathbb{R}^{n}$ and $t \in T$, where we set $r=|x| / t^{1 / 2}$. Using this notation, we calculate $u_{t}$ and $\triangle u$ :

$$
\begin{aligned}
& u_{t}(x, t)=-\frac{n}{2 t^{n / 2+1}} w(r)-\frac{1}{2 t^{n / 2+1}} r w^{\prime}(r), \\
& u_{x_{i}}(x, t)=\frac{1}{t^{n / 2+1 / 2}} w^{\prime}(r) \frac{x_{i}}{|x|}, \\
& u_{x_{i} x_{i}}(x, t)=\frac{1}{t^{n / 2+1 / 2}}\left(\frac{1}{t^{1 / 2}} w^{\prime \prime}(r) \frac{x_{i}^{2}}{|x|^{2}}+w^{\prime}(r)\left(\frac{1}{|x|}-\frac{x_{i}^{2}}{|x|^{3}}\right)\right) .
\end{aligned}
$$

So, we have

$$
\begin{aligned}
\triangle & u(x, t)-u_{t}(x, t) \\
& =\frac{1}{t^{n / 2+1}}\left(w^{\prime \prime}(r)+\frac{n-1}{r} w^{\prime}(r)+\frac{r}{2} w^{\prime}(r)+\frac{n}{2} w(r)\right) \\
& =\frac{1}{r^{n-1}} \frac{1}{t^{n / 2+1}}\left(\left(r^{n-1} w^{\prime \prime}(r)+(n-1) r^{n-2} w^{\prime}(r)\right)+\frac{1}{2}\left(r^{n} w^{\prime}(r)+n r^{n-1} w(r)\right)\right) \\
& =\frac{1}{r^{n-1}} \frac{1}{t^{n / 2+1}}\left(r^{n-1} w^{\prime}(r)+\frac{r^{n}}{2} w(r)\right)^{\prime}
\end{aligned}
$$

for all $x \in \mathbb{R}^{n}, t \in T$ with $r>0$. Moreover, from the last equality and (2.3), it follows that

$$
\begin{aligned}
\left|\Delta u(x, t)-u_{t}(x, t)\right| & =\frac{1}{r^{n-1}} \frac{1}{t^{n / 2+1}}\left|\left(r^{n-1} w^{\prime}(r)+\frac{r^{n}}{2} w(r)\right)^{\prime}\right| \\
& \leq \varphi_{1}(r) \psi(t)
\end{aligned}
$$

or

$$
\left|\left(r^{n-1} w^{\prime}(r)+\frac{r^{n}}{2} w(r)\right)^{\prime}\right| \leq r^{n-1} \varphi_{1}(r) t^{n / 2+1} \psi(t)
$$


for all $r>0$ and $t \in T$. In view of (2.2), we have

$$
-c r^{n-1} \varphi_{1}(r) \leq\left(r^{n-1} w^{\prime}(r)+\frac{r^{n}}{2} w(r)\right)^{\prime} \leq c r^{n-1} \varphi_{1}(r)
$$

for any $r>0$.

We integrate each term of the last inequality from $r$ to $\infty$ and take account of the definition of $U$ to get

$$
-c \int_{r}^{\infty} s^{n-1} \varphi_{1}(s) d s \leq-r^{n-1} w^{\prime}(r)-\frac{r^{n}}{2} w(r) \leq c \int_{r}^{\infty} s^{n-1} \varphi_{1}(s) d s
$$

or

$$
\left|w^{\prime}(r)+\frac{r}{2} w(r)\right| \leq \frac{c}{r^{n-1}} \int_{r}^{\infty} s^{n-1} \varphi_{1}(s) d s
$$

for all $r>0$.

According to [19, Theorem 1], together with (2.1), there exists a (unique) constant $\gamma \in \mathbb{R}$ such that

$$
\left|w(r)-\frac{\gamma}{(4 \pi)^{n / 2}} e^{-r^{2} / 4}\right| \leq c e^{-r^{2} / 4} \int_{r}^{\infty} \frac{e^{u^{2} / 4}}{u^{n-1}} \int_{u}^{\infty} s^{n-1} \varphi_{1}(s) d s d u
$$

for all $r>0$, or equivalently

$$
\left|u(x, t)-\frac{\gamma}{(4 \pi t)^{n / 2}} e^{-|x|^{2} / 4 t}\right| \leq \frac{c}{t^{n / 2}} e^{-|x|^{2} / 4 t} \int_{|x| / t^{1 / 2}}^{\infty} \frac{e^{u^{2} / 4}}{u^{n-1}} \int_{u}^{\infty} s^{n-1} \varphi_{1}(s) d s d u
$$

for all $x \in \mathbb{R}^{n}$ and $t \in T$ with $|x| / t^{1 / 2}>0$, which proves the validity of inequality (2.4), and in view of (2.6), it is not difficult to prove that $u_{0}(x, t)$ is a solution of the heat equation, i.e., $\triangle u_{0}(x, t)-\frac{\partial}{\partial t} u_{0}(x, t)=0$.

If we replace $x$ with $x-y$ and multiply each term by $|g(y)|$, and if we integrate all terms in the last inequality over $\mathbb{R}^{n}$, then we obtain

$$
\begin{aligned}
& -(4 \pi)^{n / 2} c D \int_{\mathbb{R}^{n}} u_{0}(x-y, t)|g(y)| d y \\
& \quad \leq \int_{\mathbb{R}^{n}} u(x-y, t) g(y) d y-\gamma \int_{\mathbb{R}^{n}} u_{0}(x-y, t) g(y) d y \\
& \quad \leq(4 \pi)^{n / 2} c D \int_{\mathbb{R}^{n}} u_{0}(x-y, t)|g(y)| d y
\end{aligned}
$$

for all $x, y \in \mathbb{R}^{n}$ and $t \in T$. If we define $u_{1}(x, t)$ as in (2.6) for any $x \in \mathbb{R}^{n}$ and $t \in T$, following the proof of [18, Theorem 1 in Section 2.3], we can then easily prove that

$$
\triangle u_{1}(x, t)-\frac{\partial}{\partial t} u_{1}(x, t)=0
$$

for all $x \in \mathbb{R}^{n}$ and $t \in T$ with $|x| / t^{1 / 2}>0$, which shows the validity of inequality (2.5).

\section{Remark 2.2}

(i) The linearity of solutions of heat equation (1.1) implies that $\gamma u_{0}(x, t)$ and $\gamma u_{1}(x, t)$ are also solutions of the heat equation. 
(ii) As in the proof of [18, Theorem 1 in Section 2.3], we can show that

$$
\lim _{\substack{(x, t) \rightarrow\left(x_{0}, 0\right) \\ x \in \mathbb{R}^{n}, t>0}} u_{1}(x, t)=g\left(x_{0}\right)
$$

for each $x_{0} \in \mathbb{R}^{n}$.

(iii) If a function $\varphi_{1}:[0, \infty) \rightarrow[0, \infty)$ satisfies

$$
\int_{u}^{\infty} s^{n-1} \varphi_{1}(s) d s=O\left(u^{n} e^{-\alpha u^{2}}\right)
$$

for all $u \geq 0$ and for some $\alpha>1 / 4$, then there exists a positive number $A$ such that

$$
\begin{aligned}
D & =\int_{0}^{\infty} \frac{e^{u^{2} / 4}}{u^{n-1}} \int_{u}^{\infty} s^{n-1} \varphi_{1}(s) d s d u \\
& \leq \int_{0}^{\infty} A u e^{(1 / 4-\alpha) u^{2}} d u \\
& =\frac{2 A}{4 \alpha-1}<\infty,
\end{aligned}
$$

i.e., $\varphi_{1}$ satisfies condition (2.1).

\section{Competing interests}

The author declares that he has no competing interests.

\section{Authors' contributions}

The author declares that this paper is his original paper.

\section{Acknowledgements}

This research was supported by the Basic Science Research Program through the National Research Foundation of Korea (NRF) funded by the Ministry of Education (No. 2013R1A1A2005557).

Received: 4 August 2013 Accepted: 1 October 2013 Published: 07 Nov 2013

\section{References}

1. Alsina, C, Ger, R: On some inequalities and stability results related to the exponential function. J. Inequal. Appl. 2 , 373-380 (1998)

2. Brillouet-Belluot, N, Brzdek, J, Cieplinski, K: On some recent developments in Ulam's type stability. Abstr. Appl. Anal. 2012, Article ID 716936 (2012). doi:10.1155/2012/716936

3. Czerwik, S: Functional Equations and Inequalities in Several Variables. World Scientific, River Edge (2002)

4. Hyers, DH: On the stability of the linear functional equation. Proc. Natl. Acad. Sci. USA 27, $222-224$ (1941)

5. Hyers, DH, Isac, G, Rassias, TM: Stability of Functional Equations in Several Variables. Birkhäuser, Boston (1998)

6. Jung, S-M: Hyers-Ulam-Rassias Stability of Functional Equations in Nonlinear Analysis. Springer Optimization and Its Applications, vol. 48. Springer, New York (2011)

7. Rassias, TM: On the stability of the linear mapping in Banach spaces. Proc. Am. Math. Soc. 72, 297-300 (1978)

8. Ulam, SM: Problems in Modern Mathematics. Wiley, New York (1964)

9. Obłoza, M: Hyers stability of the linear differential equation. Rocznik Nauk.-Dydakt. Prace Mat. 13, $259-270$ (1993)

10. Obłoza, M: Connections between Hyers and Lyapunov stability of the ordinary differential equations. Rocznik Nauk.-Dydakt. Prace Mat. 14, 141-146 (1997)

11. Miura, T, Jung, S-M, Takahasi, S-E: Hyers-Ulam-Rassias stability of the Banach space valued linear differential equations $y^{\prime}=\lambda y$. J. Korean Math. Soc. 41, 995-1005 (2004)

12. Takahasi, S-E, Miura, T, Miyajima, S: On the Hyers-Ulam stability of the Banach space-valued differential equation $y^{\prime}=\lambda y$. Bull. Korean Math. Soc. 39, 309-315 (2002)

13. Jung, S-M, Lee, K-S: Hyers-Ulam stability of first order linear partial differential equations with constant coefficients. Math. Inequal. Appl. 10, 261-266 (2007)

14. Prastaro, A, Rassias, TM: Ulam stability in geometry of PDE's. Nonlinear Funct. Anal. Appl. 8, 259-278 (2003)

15. Lungu, N, Popa, D: Hyers-Ulam stability of a first order partial differential equation. J. Math. Anal. Appl. 385, 86-91 (2012)

16. Hegyi, B, Jung, S-M: On the stability of Laplace's equation. Appl. Math. Lett. 26, 549-552 (2013)

17. Hegyi, B, Jung, S-M: On the stability of heat equation. Abstr. Appl. Anal. (in press) 
18. Evans, LC: Partial Differential Equations. Graduate Studies in Mathematics, vol. 19. American Mathematical Society, Providence (1998)

19. Jung, S-M: Hyers-Ulam stability of linear differential equations of first order, II. Appl. Math. Lett. 19, $854-858$ (2006)

10.1186/1029-242X-2013-475

Cite this article as: Jung: On the stability of the heat equation with an initial condition. Journal of Inequalities and Applications 2013, 2013:475

Submit your manuscript to a SpringerOpen ${ }^{\circ}$ journal and benefit from:

- Convenient online submission

- Rigorous peer review

- Immediate publication on acceptance

Open access: articles freely available online

- High visibility within the field

- Retaining the copyright to your article

Submit your next manuscript at $>$ springeropen.com 